trường hợp có phân nhóm hỗn hợp, do cấu trúc dị dạng tĩnh mạch lan toả, cho nên có thể phối hợp nhiêu loại cho từng vị trí. Đối với dị dạng động tĩnh mạch, có nhiều bảng phân loại dị dạng động tĩnh mạch như Do, Yakes W. F mỗi bảng phân loại có đặc tính riêng. Bảng phân loại của tác giả Do dễ hiểu, áp dụng cho dị dạng động tĩnh mạch ngoại biên, tuy nhiên không đầy đủ bản chất của dị dạng động tĩnh mạch (Hình 1). Dựa trên bảng phẩn loại của Do, Yakes W. $F$ đã cải biên và đưa ra bảng phân loại theo Yakes, lột tả được đầy đủ tính chất của dị dạng động tĩnh mạch. Theo Yakes, phân loại dị dạng động tĩnh mạch có bốn types từ I đến IV, trong đó trong type II và III, có hai phân loại nhỏ là IIA, IIB và IIIA và IIIB, khác nhau về dẫn lưu tĩnh mạch. Riêng type I chính là thông nối trực tiếp động tĩnh mạch, nằm trong xếp loại của dị dạng mạch máu theo phân loại ISSVA 2014 (Hình 2). Theo nghiên cứu của chúng tôii, type IV chiếm tỷ lệ cao nhất 43,8\%, riêng hỗn hợp, chính là những dị dạng sau khi điều trị, làm thay đổi cấu trúc nhân dị dạng, hoặc nhiều nhân dị dạng lan toả, nên phân loại được xếp vào nhóm hồn hợp?

\section{KẾT LUẬN}

Siêu âm là phương tiện đầu tay trong chẩn đoán dị dạng mạch máu. CLVT và CHT giúp chẩn đoán chính xác, mức độ lan rộng và tương quan với các cấu trúc xung quanh, ngoài ra còn phân loại cũng như đánh giá sau điều trị.

TÀI LIỆU THAM KHẢO

1. Lee Byung-B., Laredo J., Neville R. F., et al. (2015), "Epidemiology of vascular malformations", In: Hemangiomas and Vascular Malformations, Springer, pp. 165-169.

2. Nguyễn Công Minh (2013), "Đánh giá điều trị dị dạng mạch máu bẩm sinh ở người lớn trong 6 năm (2005-2010)". Tạp chí Y học TPHCM, 17.

3. Tasnádi G. (1993), "Epidemiology and etiology of congenital vascular malformations". Semin Vasc Surg, 6 (4), pp. 200-3.

4. Arnold R., Chaudry G. (2011), "Diagnostic imaging of vascular anomalies". Clin Plast Surg, 38 (1), pp. 21-9.

5. Trop I., Dubois J., Guibaud L., et al. (1999), "Soft-tissue venous malformations in pediatric and young adult patients: diagnosis with Doppler US". Radiology, 212 (3), pp. 841-5.

6. Olivieri B., White C. L., Restrepo R., et al. (2016), "Low-Flow Vascular Malformation Pitfalls: From Clinical Examination to Practical Imaging Evaluation--Part 2, Venous Malformation Mimickers". AJR Am J Roentgenol, 206 (5), pp. 952-62.

7. Yakes W. F. (2015), "Yakes' AVM classification system". Journal of Vascular and Interventional Radiology, 26 (2), pp. S224.

\title{
TÁC DƯNG KHÔNG MONG MUỐN CỦA PHÁC Đồ PEMETREXED - CARBOPLATIN ĐIỀU TRI UNG THƯ PHỔI KHÔNG TẾ BÀO NHỎ SAU KHÁNG THỨ PHÁT VỚI THUỐC ỨC CHẾ EGFR TYROSINE KINASE
}

\section{TÓM TẮT}

Mục tiêu: Đánh giá tác dụng không mong muốn của phác đồ Pemetrexed - Carboplatin điều trị bước hai bệnh nhân ung thư khổi không tế bào nhỏ sau kháng thứ phát thuốc ức chế Tyrosine Kinase. Đối tượng và phương pháp: 46 bệnh nhân ung thư phổi không tế bào nhỏ giai đoạn tiến xa có đột biến EGFR, kháng thứ phát với TKIs, không có hoặc không biết đột biến T790M, điều trị hoá chất phác đồ Pemetrexed - Carboplatin. Nghiền cứu hồi cứu. Đánh giá tác dụng không mong muốn theo tiêu chuẩn CTCAE4.0. Kết quả: Hạ bạch cầu 10,6\%, Hạ bạch

\footnotetext{
*Bệnh viện $K$ Trung ương

**Bệnh viện Hữu Nghi Hà Nội

Chịu trách nhiệm chính: Nguyễn Thị Thái Hoà,

Email; bshoabvk@gmail.com

Ngày nhận bài: 9/3/2021

Ngày phản biện khoa học: 4/4/2021

Ngày duyệt bài: 2/5/2021
}

\section{Nguyễn Thị Thái Hoà*, Mai Thanh Huyền**}

câu trung tính 12,6\%, Giảm huyết sắc tố 31,6\%, Giảm tiểu cầu $0 \%$. Tăng men gan $6 \%$, Độc tính trên thân $0 \%$, Nôn $6.5 \%$, Tiêu chảy 4,2\%. Tác dụng phụ độ 3 trở lên rất hiếm gặp, không có tử vong do điều trị. Kết luâan: Phác đồ Pemetrexed - Carboplatin được dung nạp tốt ở bệnh nhân UTPKTBN sau kháng thứ phát thuốc cức chể Tyrosine Kinase

Tư khoá: Tác dụng không mong muốn, độc tính, dung nạp

\section{SUMMARY}

SIDE-EFFECTS OF PEMETREXED-CARBOPLATIN REGIMEN FOR ADVANCED STAGE NON-SMAL

\section{CELL LUNG CANCER AFTER EGFR TKIs} ACCQUIRED RESISTANCE

Objective: To evaluate the side -effects of the seconde - line Pemetrexed - Carboplatin regimen in advanced non-small cell lung cancer after accquired resistance to EGFR TKIs treated. Objects and methods: 46 patients with advanced non-small cell lung cancer with EGFR mutation, secondary resistance 
to TKIs, no or unknown T790M mutation, treatment withPemetrexed - Carboplatin. Retrospective studies. Evaluate side - effects according to CTCAE4.0 criteria. Results: Leukopenia $10.6 \%$, Neutropenia 12.6\%, Reduced hemoglobin $31.6 \%$, Thrombocytopenia $0 \%$. Increased liver enzymes $6 \%$, Renal toxicity $0 \%$, Vomiting $6.5 \%$, Diarrhea $4.2 \%$. Side effects of grade 3 or higher are very rare, with no death due to treatment. Conclusion: The Pemetrexed Carboplatin regimen is well tolerated in patients with NSCLC after secondary resistance to the inhibitor Tyrosine Kinase.

Keywords: Undesirable effects, toxicity, tolerance.

\section{I. ĐĂT VẤN ĐỀ}

Điều tri ung thư phổi không tế bào nhỏ (UTPKTBN) giai đoạn tiến xa nhằm mục tiêu kéo dài sống thêm, giảm triệu chứng, nâng cao chất lượng sống. Hoá trị bước 1 cho giai đoạn này thường là phác đồ hoá chất bộ đôi, kết hợp nhóm platinum với một thuốc thế hệ 3 như Docetaxel, Paclitaxel, Gemcitabine, Pemetrexed. Phác đồ Pemetrexed - Carboplatin là một trong những phác đồ được sử dụng cho điều trị bước 1 UTPKTBN giai đoạn IV, loại không phải tế bào vảy.Theo các nghiên cứu, phác đồ cho tỷ lệ đáp ứng là $31-42 \%$, các tác dụng không mong muốn của phác đồ chấp nhận được $[1,2,3]$. Trên đối tượng bệnh nhân cao tuổi, phác đồ này cũng được dung nạp tốt với tỷ lệ đáp ứng là 34\% [4].

Với ung thư phổi không tế bào nhỏ có đột biến EGFR, điều trị bước 1 thường là các thuốc ức chế Tyrosine kinase (TKIs) vì cho hiệu quả cao hơn hoá trị bộ đôi và dung nạp thuốc tốt hơn. Khi bệnh tiến triển (kháng thuốc), 50-60\% các trường hợp được phát hiện có đột biến kháng thuốc T790M. Khi kháng thuốc EGFR TKIs, phác đồ này cho tỷ lệ đáp ứng là $31 \%$ và sống không tiến triển bệnh là4,4 tháng [5].

Tại Việt Nam, phác đồ Pemetrexed - Paltinum đã được đánh giá kết quả điều trị bước 1 UTPKTBN không vảy, thời gian sống thêm không tiến triển trung bình là 5,9 $\pm 0,2$ tháng, trungvịlà 5,8 tháng, các độc tính có thể gặp thường ở mức độ nhe [6]. Tuy nhiên, khi kháng thuốc thứ phát, thể trạng bệnh nhân có thể yếu hơn so với điêuu trị từ đầu, các tác dụng không mong muốn có thể thay đổi về tỷ lệ cũng như mức độ. Tại Việt Nam chưa có nghiên cứu nào đánh giá về tác dụng không mong muốn của phác đồ Pemetrexed - Carboplatin trên đối tượng bệnh nhân đã tiến triển sau EGFR TKIs.

Vì vậy, chúng tôi tiến hành đề tài này nhằm mục tiêu: "Đánh giá các tác dụng không mong muốn củaphác đồ Pemetrexed - Carboplatin trên bệnh nhân UTPKTBN sau kháng thứ phát với

\section{EGFR TKIs"}

\section{II. ĐỐI TƯợNG VÀ PHƯƠNG PHÁP NGHIÊN CỨU}

Bệnh nhân UTPKTBN giai đoạn IIIB, IV xác định tiến triển sau điều trị với TKİs, điều trị bằng phác đồ Pemetrexed - Carboplatin tại Bệnh viện $K$ và Bệnh viện Hữu Nghị từ 1/2017 - 8/2020.

2.1.Tiêu chuẩn lựa chọn: - Chỉ số toàn trạng (Performance status - PS): 0,1

- Mô bệnh học: ung thư biểu mô tuyến

- Có đột biến EGFR thuộc loại nhạy cảm thuốc TKIs; Kháng thứ phát sau điều trị bước 1 bằng TKIs mà chưa nhận thêm điều trị nào khác

- Không có hoặc không biết tình trạng đột biến T790M sau kháng TKIs

\subsection{Tiêu chuẩn loại trừ}

- Không có hồ sơ bệnh án đầy đủ

- Không có dữ liệu để đánh giá đáp ứng

\subsection{Phương pháp nghiên cứu}

2.3.1. Thiết kế nghiên cứu: Nghiên cứu mô tả hồi cứu cắt ngang

2.3.2. Mẫu nghiên cứu. Lựa chọn cỡ mẫu thuận tiện.

2.3.3. Phương pháp tiến hành. Bệnh nhân điêu trị phác đồPemetrexed - Carboplatin: Pemetrexed $500 \mathrm{mg} / \mathrm{m}^{2}$ truyền tĩnh mạch ngày 1; Carboplatin AUC 5-6 truyền tĩnh mạch ngày 1. Chu kỳ 21 ngày.

Chuẩn bị trước khi trị liệu: Để giảm tần xuất và mức độ nghiêm trọng của các phản ứng da, cần cho BN sử dụng một corticosteroid với liều tương đương dexamethason $4 \mathrm{mg}$ uống 2 lần mỗi ngày vào ngày trước, ngày tiêm truyền, và ngày sau khi tiêm truyền Pemetrexed. BN phải được uống acid folic hoặc một chế phẩm nhiều vitamin có chứa acid folic (350-1000 mcg) hàng ngày. Ít nhất phải uống 5 liều acid folic trong 7 ngày trước khi dùng liều Pemetrexed đầu tiên, và phải tiếp tục uống trong toàn bộ đợt điều trị và trong 21 ngày sau liêu Pemetrexed cuối cùng. $B N$ cũng phải được tiêm bắp vitamin B12 (1000 mcg) trong tuần trước liều Pemetrexed đầu tiên và cứ 3 CK một lần sau đó. Những lần tiêm vitamin B12 tiếp sau có thể vào cùng ngày với Pemetrexed.

Tác dụng không mong muốn dựa trên ghi nhận trong hồ sơ bệnh án qua khám lâm sàng và cận lâm sàng trước mỗi đợt hoá trị. Đánh giá dựa trên tiêu chuẩn CTCAE4.0

2.4. Xử lý số liệu. Số liệu được xử lý bằng phần mềm thống kể SPSS 16.0. Phân tích sống thêm theo phương pháp Kaplan-Meier.

\section{KẾT QUẢ NGHIÊN CỨU}

\section{1. Đặc điểm bệnh nhân}




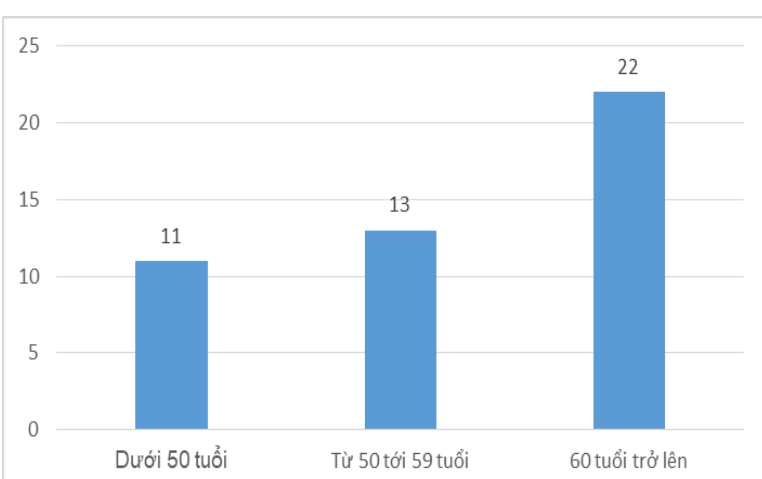

Biểu đồ 3.1. Phân bố theo nhóm tuổi

Tuổi trung bình: 57,3 \pm 9,0 năm Min: 39 Max: 77

Nhận xét: Tuổi trung bình là 57 tuổi, trẻ nhất là 39 tuổi, lớn nhất 77 tuổi. Nhóm tuổi dưới 60 tuổi chiếm ưu thế hơn $(52,17 \%$ so với $47,83 \%)$

Bảng 3.1. Đặc điểm bệnh nhân nghiên cứu

\begin{tabular}{|c|c|c|c|c|}
\hline \multicolumn{2}{|c|}{ Đặc điểm bệnh nhân } & $\mathbf{n}$ & $\mathbf{\%}$ & Tống \\
\hline \multirow{2}{*}{ Nhóm tuổi } & $\geq 60$ & 22 & 47,8 & \multirow{2}{*}{46} \\
\cline { 2 - 4 } & $<60$ & 24 & 52,2 & \\
\hline \multirow{2}{*}{ Giới } & Nam & 24 & 52,2 & \multirow{2}{*}{46} \\
\cline { 2 - 4 } & Nữ & 22 & 47,8 & \\
\hline
\end{tabular}

\begin{tabular}{|c|c|c|c|c|}
\hline \multirow{2}{*}{ PS } & 0 & 35 & 76 & \multirow{2}{*}{46} \\
\cline { 2 - 4 } & 1 & 11 & 24 & \\
\hline \multirow{2}{*}{ Giai đoạn } & IIIB & 13 & 28,2 & \multirow{2}{*}{46} \\
\cline { 2 - 4 } & IV & 33 & 71,8 & \\
\hline \multirow{2}{*}{ Di căn não } & Có & 11 & 24 & \multirow{2}{*}{46} \\
\cline { 2 - 4 } & Không & 35 & 76 & \\
\hline
\end{tabular}

Bảng 3.2. Số chu ki điều trị Pemetrexed - Carboplatin

\begin{tabular}{|c|c|c|}
\hline Số chu kì & Số BN (n) & Tỷ lệ (\%) \\
\hline 2 CK & 17 & $37.0 \%$ \\
\hline 4 CK & 14 & $30.4 \%$ \\
\hline 6 CK & 6 & $13.0 \%$ \\
\hline$>6$ CK & 9 & $19.6 \%$ \\
\hline
\end{tabular}

Nhận xét: Số BN nhận được số chu kì điều trị từ 4 CK chiếm đại đa số

Bảng 3.3. Liều hoá chất

\begin{tabular}{|c|c|c|}
\hline $\begin{array}{c}\text { Liêuu hoá chất } \\
(\%)\end{array}$ & $\begin{array}{c}\text { Số bệnh } \\
\text { nhân (n) }\end{array}$ & Tỷ lệ (\%) \\
\hline 100 & 46 & $100,0 \%$ \\
\hline $85-<100$ & 0 & $0,0 \%$ \\
\hline
\end{tabular}
hoá chất

3.2. Tác dụng không mong muốn hệ tạo huyết

Bảng 3.4. Tác dụng không mong muốn trên hệ tạo huyêt

\begin{tabular}{|c|c|c|c|c|c|c|c|c|}
\hline \multirow{3}{*}{$\begin{array}{c}\text { Tác dụng không mong muốn } \\
\text { trên hệ tạo huyết }\end{array}$} & \multicolumn{8}{|c|}{ Độ độc tính (n = 215 CK) } \\
\hline & \multicolumn{2}{|c|}{$\mathbf{1}$} & \multicolumn{2}{|c|}{2} & \multicolumn{2}{|c|}{3} & \multicolumn{2}{|c|}{4} \\
\hline & $\mathbf{n}$ & $\%$ & $\mathbf{n}$ & $\%$ & $\mathbf{n}$ & $\%$ & $\mathbf{n}$ & $\%$ \\
\hline Giảm bach câuu & 19 & 8,8 & 0 & 0,0 & 3 & 1,4 & 1 & 0,4 \\
\hline Giảm bạch cầu hạt & 21 & 9,8 & 1 & 0,4 & 4 & 1,9 & 1 & 0,4 \\
\hline Giảm huyết sắc tố & 51 & 23,7 & 17 & 7,9 & 0 & 0,0 & 0 & 0,0 \\
\hline Giảm tiếu cầu & 0 & 0,0 & 0 & 0,0 & 0 & 0,0 & 0 & 0,0 \\
\hline
\end{tabular}

Nhận xét: Độc tính trên hệ tạo huyết chủ yếu ở mức độ 1, giảm huyết sắc tố chiếm tỉ lệ cao nhất chiếm $31,6 \%$ nhửng chỉ gặp độ 1 và độ 2 .

Giảm bach cầu và bạch câuu hạt gặp 23,1\%, trong đó có 3 chu kỳ giảm bạch cầu độ 3 chiếm 1,4\% và 1 chu kì giảm bạch cầu độ 4 chiếm $0,4 \%$.

Không ghi nhận trường hợp nào có giảm tiểu cầu.

3.3. Tác dụng không mong muốn ngoài hệ tạo huyết

Bảng 3.5. Một số tác dụng phỵ ngoài hệ tạo huyêt

\begin{tabular}{|c|c|c|c|c|c|c|c|c|}
\hline \multirow{3}{*}{$\begin{array}{c}\text { Tác dụng không mong muốn } \\
\text { ngoài hệ tạo huyết }\end{array}$} & \multicolumn{8}{|c|}{ Độ độc tính (n = 215 CK) } \\
\hline & \multicolumn{2}{|c|}{1} & \multicolumn{2}{|c|}{2} & \multicolumn{2}{|c|}{3} & \multicolumn{2}{|c|}{4} \\
\hline & $\mathbf{n}$ & $\%$ & $\mathbf{n}$ & $\%$ & $\mathbf{n}$ & $\%$ & $\mathbf{n}$ & $\%$ \\
\hline Tăng SGOT, SGPT & 13 & 6,0 & 0 & 0,0 & 0 & 0,0 & 0 & 0,0 \\
\hline Tăng Creatinin máu & 0 & 0,0 & 0 & 0,0 & 0 & 0,0 & 0 & 0,0 \\
\hline Tăng ure & 0 & 0,0 & 0 & 0,0 & 0 & 0,0 & 0 & 0,0 \\
\hline Nôn, buồn nôn & 14 & 6,5 & 0 & 0,0 & 0 & 0,0 & 0 & 0,0 \\
\hline Ía chảy & 9 & 4,2 & 0 & 0,0 & 0 & 0,0 & 0 & 0,0 \\
\hline
\end{tabular}

Nhận xét: Tăng SGOT, SGPT gặp ở 13 chu kỳ chiếm $6 \%$ và chỉ tăng ở độ 1, không ảnh hưởng tới chu kì điều trị tiếp theo. Không có trường hợp nào có tăng ure và creatinin máu. $6,5 \%$ số CK bệnh nhân có buồn nôn và nôn nhưng cũng chỉ là độ 1 .

Có 9 chu kỳ bệnh nhân ỉa chảy độ 1 (4,2\%) đều là những bệnh nhân có hạ bạch cầu. 


\section{BÀN LUẬN}

Điều trị UTPKTBN giai đoạn tiến triển và di căn ngoài mục tiêu kéo dài thời gian sống thêm cho bệnh nhẩn, chất lượng cuộc sống của bệnh nhân là một mục tiêu hết sức quan trọng. Độc tính của phác đồ hoá trị là hết sức quan trọng, đặc biệt khi thể trạng của bệnh nhân suy giảm nhiều.

Các bệnh nhân có đột biến EGFR, điều trị bước 1 thường là các EGFR TKIs vì ưu thế hơn hoá trị về tỷ lệ đáp ứng, sống thêm không tiến triển bệnh, dung nạp thuốc. Đột biến T790M là nguyên nhân của $50-60 \%$ trường hợp kháng thuốc TKIs. Trong trường hợp có đột biến kháng thuốc, Osimertinib là lựa chọn tối ưu. Những bệnh nhân không có hoặc không biết tình trạng đột biến T790M, hoá trị là lựa chọn thay thế. Tuy nhiên, khi bệnh kháng thuốc, tình trạng chung của bệnh nhân thường xâu, lựa chọn phác đồ điều trị ít độc tính là quan tâm hàng đầu với thày thuốc lâm sàng. Phác đồ Pemetrexed carboplatin đã chứng minh được hiệu quả và an toàn trong các thử nghiệm lâm sàng, là lựa chọn hợp lý điều trị ung thư phổi sau kháng EGFR TKIs.

Trong nghiên cứu của chúng tôi, hạ bạch cầu gặp ở 10,6\% trường hợp, trong đó có 3 trường hợp hạ bạch câu độ 3 và 1 trường hợp hạ bạch cầu độ 4 . Hạ bạch cầu trung tính gặp ở 12,6\% trường hợp nhưng chủ yếu ở độ 1 . Chúng tôi gặp giảm huyết sắc tố với tỉ lệ cao nhất 31,6 \% số trường hợp, trong đó giảm độ 1 chiếm $23,7 \%$, giảm độ 2 chiếm 7,9\%, không có trường hợp nào giảm độ 3 , độ 4 và cũng không có trường hợp nào được ghi nhận giảm tiểu cầu. Hầu hết các tác dụng phụ đều ở mức độ nhẹ, và không ảnh hưởng đến liệu trình và liều điều trị cho bệnh nhân. Điều này cũng rất phù hợp với các nghiên cứu khác đã được công bố ở nước ngoài về độc tính nhe khi kết hợp Pemetrexed với Carboplatin trong điều trị ung thư phổi. Đây cũng là ưu điểm của phác đồ.Nếu so sánh với kết quả nghiên cứu của tác giả Trương Văn Sáng (2019) cũng điều trị phác đồ này cho bệnh nhân UTPKTBN giai đoan lan tràn nhưng ở bước 1 thì cũng cho kết quả tương tự còn với kết quả nghiên cứu của tác giả Trần Thị Chung (2019) ở nhóm đối tượng tương đồng nhưng khác phác đồ (Paclitaxel - Carboplatin) thì trong nghiên cứu của chúng tôi cho kết quả thấp hơn (hạ bạch cầu $10,6 \%$ so với 14,2\%, giảm huyết sắc tố $31,6 \%$ so với $42,9 \%)[6,7]$. Nói chung, tác dụng phụ trên hệ tạo huyế tthường nhẹ và có khả năng hồi phục.

Trong nghiên cứu của chúng tôi, tỷ lệ tăng men gan gặp ở 6\% số trường hợp, tất cả độc tính đều ở mức độ nhe (độ 1 ), tăng creatine máu, ure máu không gặp trường hợp nào. Các hóa chất trong phác đồ được chuyển hóa chủ yếu ở gan, mặ̆t khác nước ta là nước có tỷ lệ nhiễm vi rút viêm gan $B$ khá cao, nếu bệnh nhân có viêm gan $B$ kết hợp thì có thể dẫn đển thể tối cấp và gây tử vong. Do vậy, các bệnh nhân trong nghiên cứu của chúng tôi đều được khai thác kỹ tiền sử viêm gan, xét nghiệm vi rút viêm gan và điều trị nếu có chỉ định. Sau khi dùng thuốc trợ gan, xét nghiệm đã trở về bình thường, không có bệnh nhân nào phải giảm liều thuốc hoá chất hay ngừng điều trị. Một trong các tác dụng phụ hay gặp nhất khi hóa trị là tình trạng buồn nôn và nôn. Để hạn chế tác dụng phụ này, trong phác đồ điều trị hoá chất, tất cả các $B N$ đều được dùng thuốc chống nôn trước và sau truyền hoá chất. Trong nghiên cứu của chúng tôi tác dụng không mong muốn nônvàbuồnnôngặp ở mứcđộnhẹvớitilệ $\quad 6,5 \%$ khôngảnhhưởngđếnsinhhoạt, có 4, $\quad$ co trườnghợp có tiêuchảynhưngcũng ở mức độ 1.

\section{KẾT LUÂN}

Đánh giá tác dụng không mong muốn của phác đồ Pemetrexed - Carboplatin cho bệnh nhân UTPKTBN sau kháng thứ phát với thuốc ức chế Tyrosine Kinase, chúng tôi thu được những kết quả sau: - Hạ bạch cầu 10,6\%, Hạ bạch cầu trung tính $12,6 \%$

- Giảm huyết sắc tố với tỉ lệ cao nhất 31,6 \%

- Giảm tiểu cầu $0 \%$

- Tăng men gan $6 \%$

- Độc tính trên thận 0\%

- Nồn $6.5 \%$

- Tiêu chảy 4,2\%

- Tác dụng phụ độ 3 trở lên rất hiếm gặp, không có tử vong do điều trị

\section{TÀI LIẸU THAM KHẢO}

1. Scagliotti G., Park K., Patil S., Rolski J., Goksel T., Martins R., et al (2009). Survival without toxicity for cisplatin plus Pemetrexed versus cisplatin plus gemcitabine in chemonaive patients with advanced non-small cell lung cancer: a risk-benefit analysis of a large phase III study. Eur J Cancer, 45, 2298-2303.

2. Scagliotti G.V. (2005). Pemetrexed plus carboplatin or oxaliplatin in advanced non small cell lung cancer. Semin Oncol, 32(2 Suppl 2), S5-8

3. Metro G., Chiari R., Mare M.et al. (2011), Carboplatin plus pemetrexed for platinum pretreated, advanced non-small cell lung cancer: a retrospective study with pharmacogenetic evaluation. Cancer Chemother Pharmacol, 68(6), 1405-1412. 
4. Ito $M$, Horita $N$, Nagashima $A$, Kaneko $\mathbf{T}(2019)$. Carboplatin plus pemetrexed for the elderly incurable chemo-naive nonsquamous nonsmall cell lung cancer: Meta-analysis. Asia Pac J Clin Oncol. 2019 Apr;15(2):e3-e10. doi: 10.1111/ajco.12837. Epub 2018 Jan 8.PMID: 29316288

5. Tony S. Mok, Yi-Long Wu, Myung-Ju Ahn, et al (2017). Osimertinib or PlatinumPemetrexed in EGFR T790M-Positive Lung Cancer. N Engl J
Med 2017; NEJMoa1612674

376:629-640DOI:

10.1056

6. Trương Văn Sáng (2019). Đánh giá kết quả điều trị phác đồ Pemetrexed - Carboplatin trên bênh nhân ung thư biểu mô tuyến của phổi giai đoan IV. Luân văn Thac sĩ Chuyên ngành Ung thư

7. Trấn Thị Chung (2019). Đánh giá kết quả hoá tri bước 2 phác đồ Paclitaxel - Carboplatin trong ung thư phổi không tế bào nhỏ sau kháng TKI tại Bệnh viện Phổi Trung ương. Luận văn Thạc sĩ Chuyên ngành Ung thư

\section{GIÁ TRI SIÊU ÂM TRONG CHẨN ĐOÁN CHẤN THƯƠNG VÀ VẾT THƯƠNG BỤNG}

\section{TÓM TẮT}

Mục tiêu: Khảo sát vai trò của siêu âm trong chẩn đoán chấn thương và vết thương bụng tại Bệnh viện Đa khoa Sài Gòn. Đối tượng và phương pháp: Nghiên cứu tiến cứu mô tả cằt ngang trên tất cả bệnh nhân có chấn thương hoặc vết thương bụng được phẫu thuật tại khoa Ngoại Tổng quát Bệnh viện Đa khoa Sài Gòn từ 1/1/2019 - 31/12/2020. Kết quả: Tổng cộng có 96 trường hợp chấn thương hoăcc vết thương bụng được chẩn đoán và phẫu thuật. Siều âm phát hiện dịch tự do trong ổ bung độ nhạy $89.68 \%$, độ đăc hiệu $66,67 \%$. Siêu âm xác định vỡ tạng rỗng có độ nhạy $81,5 \%$, độ đặc hiệu $95,67 \%$. Trong võ tạng đặc siêu âm có độ chính xác: 90,6\%. Kết luận: Chấn thương và vết thương bụng là cấp cứu ngoại khoa. Chẩn đoán sớm, thái độ xử lý thích hợp giúp giảm tỷ lệ tử vong. Siêu âm đánh giá tập trung thương tổn là phương pháp chẩn đoán được lựa chọn đâu tiên giúp khảo sát thương tổn tạng trong ổ bụng. Độ nhay, độ chính xác của siêu âm trong chẩn đoán chấn thương và vết thương bụng khá cao. bung,

Tư khóa: Chấn thương bụng kín, vết thương thấu

\section{SUMMARY}

EVALUATION OF ULTRASONOGRAPHY FOR THE DIAGNOSIS OF BLUNT ABDOMINAL

\section{TRAUMA AND PENETRATING WOUND}

Objectives: Investigate the role of ultrasound in trauma and abdominal wound diagnosis at Saigon General Hospital. Subjects and methods:The prospective study describes cross-sectional sections on

${ }^{1}$ Bênh viện Đa khoa Sài Gòn

${ }^{2}$ Đai họ Y Đước TP. Hồ Chí Minh

${ }^{3}$ Đại hoc Y khoa Pham Ngoc Thạch

Chịu trách nhiệm chính: Nguyễn Hoàng Linh

Email: linhnguyen1967@gmail.com

Ngày nhận bài: 8/3/2021

Ngày phản biên khoa hoc: 9/4/2021

Ngày duyệt bài: 7/5/2021

\section{Nguyễn Hoàng Linh ${ }^{1}$, Nguyễn Đức Vũ ${ }^{1}$, Dương Văn Hải ${ }^{2}$, Nguyễn Công Minh ${ }^{3}$}

all patients with surgical trauma or abdominal wounds at the General Surgery Department of Saigon General Hospital from January 1, 2019 to December 31, 2020. Results: A total of 96 cases of trauma or abdominal injuries were diagnosed and operated. Ultrasound to detect free fluid in the bulb, sensitivity $89.68 \%$, specificity $66.67 \%$. Ultrasound to determine the hollow organ rupture with sensitivity $81.5 \%$, specificity $95.67 \%$. In the visceral solid, ultrasound has accuracy: $90.6 \%$. Conclusion: Injuries and abdominal injuries are surgical emergencies. Early diagnosis, appropriate treatment attitude helps to reduce mortality. Focused ultrasound is the primary diagnostic method of choice for the investigation of intra-abdominal damage. The sensitivity and accuracy of ultrasound in diagnosis of abdominal injuries and wounds is quite high.

Key words: Blunt abdominal trauma. Penetrating abdominal wound.

\section{I. ĐẶT VẤN ĐỀ}

Chấn thương và vết thương bụng là cấp cứu ngoại khoa thường gặp. Thương tổn các tạng trong ổ bụng có thể dẫn đến tử vong do mất máu, nhiễm trùng ổ bụng hay suy đa cơ quan nếu các thương tổn này không được chẩn đoán sớm và xử trí kip thời. Việc chẩn đoán sớm có thể gặp khó khăn do các triệu chứng ở vùng bụng bị che lấp hay chưa biểu hiện rõ trong bệnh cảnh đa chấn thương với nhiêuu thương tổn kết hợp. Do đó, mỗi bệnh nhân bị chấn thương hay vết thương vùng bụng cân được đánh giá một cách tích cực, kỹ lưỡng và toàn diện qua thăm khám lâm sàng, kết hợp với các phương tiện chẩn đoán hình ảnh và cận lâm sàng khác cho đên khi xác đinh được rằng các tạng trong ổ bụng không bị tổn thương [1].

Bác sĩ phải nhanh chóng xác đinh chẩn đoán, bệnh nhân bị tổn thương cơ quan nào, mức độ 